\title{
Investigating Cohesion and Coherence \\ Discourse Strategies of Chinese Students with Varied Lengths of Residence in Canada
}

Krista Leo

This study examines how three age-on-arrival ( $A O A$ ) groups of Chinese-background ESL students use two types of cohesive devices on a standardized essay exam. A discourse analysis of 90 first-year students' expository writing samples was conducted to ascertain how factors such as first language (L1) and length of residence (LOR) in Canada influence a student's ability to create cohesive and coherent writing. The study uses both quantitative and qualitative methods to explore how Canadian-born Chinese $(C B C)$ students use lexical and referential discourse markers. Twelve essay features of this group of Generation 1.5 students are compared with those of two other cohorts of Chinese students with a shorter LOR. Key writing variables that measure academic writing proficiency were quantitatively analyzed to compare the expository writings of the $C B C$ cohort with those of the later AOAs. Results indicate that synonymy and content words distinguish the writings of the CBC students from those of their later-arriving peers. A qualitative analysis of one CBC essay reveals that a more flexible and contextualized approach to evaluating writing by longterm Generation 1.5 students is required to acknowledge fully the productive lexical and discoursal strengths of these students.

Cette étude porte sur l'emploi de deux types de marqueurs de relation dans un examen à développement standardisé par des étudiants en ALS d'origine chinoise et regroupés en fonction de leur âge à l'arrivée. À partir d'échantillons de rédactions descriptives écrites par 90 étudiants de première année, nous avons fait une analyse du discours pour déterminer dans quelle mesure des facteurs tels la langue première et la durée du séjour au Canada influencent la capacité d'un étudiant à écrire un texte cohérent. L'étude a recours à des méthodes quantitatives et qualitatives pour explorer l'emploi des marqueurs discursifs lexicaux et référentiels chez les étudiants chinois nés au Canada. Nous comparons 12 éléments des rédactions écrites par ce groupe d'étudiants $G$ 1,5 à ceux de deux autres cohortes d'étudiants chinois au Canada depuis moins longtemps. Nous avons fait une analyse quantitative de variables clés qui mesurent la compétence en rédaction académique pour comparer les rédactions descriptives du groupe d'étudiants nés au Canada à celles des étudiants nés en Chine. Les résultats indiquent que les textes des deux groupes se distinguent par la synonymie et les mots-matière. Une analyse qualitative d'une rédaction d'un étudiant chinois né au Canada révèle qu'une approche plus souple et contextualisée dans l'évaluation des étudiants $G$ 1,5 est nécessaire si l'on veut pleinement reconnaitre les forces lexicales et discursives chez ce type d'étudiant. 


\section{Overview and Background to the Problem}

In recent years, the significant changes to the demographic student populations in mainstream high schools and postsecondary institutions have led to a surge in the research on academic literacy. One area of particular concern is how ESL teachers and practitioners prepare non-native English-speaker students (NNES) to fulfill the requirements of higher education. With increasing numbers of these students entering colleges and universities in Canada and the United States, the field of second-language (L2)/ESL writing research that emerged in the 1960s has flourished. Today it is an urgent priority because familiarity with academic written discourse and North American rhetorical conventions are fundamental to ensuring students' success in university. As a result, substantial research is focused on L2 writing pedagogy for international and immigrant English-language learner (ELL) students. Yet the problem of inadequate attention being paid to a rapidly growing population of students who are either native-born or long-term ELLs remains.

Rumbaut and Ima (1988) first used the term 1.5 generation to describe children of immigrants who "have traits and experiences [that] lie somewhere between those associated with the first and second generation" (pp. 1-2). According to this early study, these 1.5er students are distinguished from multilingual international students in that they have a profile that differs from conventional NNESs or ELLs attending college or university in North America. Generation 1.5 students are "circumstantial bilinguals" (Valdés, 1992, pp. 94-95), who have learned to speak English fluently through immersion in an English-speaking environment. Their vastly diverse backgrounds, motivations, and English-language training makes it difficult to pinpoint the language-learning needs of these bicultural students. In some instances, they have been tracked or labeled remedial speakers of English and thus have received inappropriate instructional language support before being mainstreamed into the K-12 system (Benesch, 2001). Harklau (Matsuda et al., 2003) points out that only in the last five years has explicit pedagogical attention been focused on Generation 1.5 learners; and research on their needs has just begun in response to their outnumbering traditional international ELLs in some US colleges.

In the Canadian context, research literature refers to this profile of second-generation ELLs as Canadian-born or 1.5 generation (Boyd, 2002). Many of these Canadian-born Chinese (CBC) students appear to have native-like fluency in speaking because their underlying academic language needs, specifically in the area of writing, are overlooked by educators. To rectify this oversight, this study focuses on the academic writing needs of this profile of university-bound Chinese students, those who are native-born or long-term residents of Canada. To gain a better understanding of the unique writing needs and characteristics of these students compared with later-arriving ELLs, the quantitative segment of this study examines two other cohorts of 
later-arriving Chinese-background learners: those who arrived at elementary school age (kindergarten to grade 7) and those who arrived at junior-high or high school age (grades 8-12).

\section{English Language Proficiency and NNES Students' Struggles with Academic Writing}

For many NNES students who enter university from high school, the need to demonstrate university-level writing competence is a daunting and overwhelming requirement. In many universities across Canada, students who were unable to achieve a satisfactory score in grade 12 English must pass an English-language proficiency (ELP) test before registering in undergraduate courses. At the University of Calgary ( $\mathrm{U}$ of $\mathrm{C}$ ), incoming students (NS and NNES) who failed to score at least 75\% on the English 30-1 Diploma exam must complete the Effective Writing Test (EWT) to prove their academic writing competence. From 1976 to 2009, students who did not pass the EWT within their first year of undergraduate studies were required to withdraw from the university. According to recent research conducted on EWT outcomes, almost $90 \%$ of students who struggled to fulfill this requirement were NNES (Douglas, 2010). Douglas's study, which compared NS and NNES students' achievement on the EWT, found that in a total sample of 745 students (comprising 561 NS students and 184 NNES) who wrote the exam, Chinese was by far the largest L1 language group represented. For many of these academically motivated Chinese students, writing academic English at the university level poses a significant barrier to their aspirations with far-reaching implications. As changes in student demographics reflect an increasing number of this profile of students entering Canadian universities, their needs must be appropriately addressed.

\section{Differentiating Between Generation 1.5 ELLs and Later-Age-on-Arrivals in Canada's Schools}

In the context of Canadian schools, educators face an ever-increasing challenge in meeting the diverse learning needs of the growing number of Generation 1.5 students in their classrooms. In her study that investigated the influence of AOA and LOR on ESL students' achievement in high school, Roessingh (2008) builds on earlier tracking studies that show older-arriving ESL students (aged 15-16) outperformed younger arrivals (aged 12-14) on the Alberta grade 12 English Language Arts (ELA) provincial exam. Further, the youngest arrivals (aged 6-11) experienced the most difficulty with academic language development despite their seeming advantage in having a greater LOR in Canada. The explanation in part for this unexpected finding is based on emerging research evidence that indicates lack of academic content vocabulary as a major stumbling block, especially for Canadian-born 
and younger-arriving ESL learners who sound fluent as a result of having acquired phonological/conversational English. Moreover, recent research shows that children of immigrants share some of the same characteristics as their older-arriving ELL counterparts, as well as those of native speakers (NS). This neither-nor profile results in the learning needs of these students being overlooked (McGinnis, 2008). Consequently, these young arrivals are at risk when they enter tertiary educational settings. As subtractive bilinguals, they compete in English with their NS peers, who read above grade level and score $80 \%$ (and higher) on the provincial grade 12 ELA exam (Roessingh \& Elgie, 2009).

\section{The Need to Initiate Canadian G 1.5 Students into the North American Academic Discourse Community}

In her study of Generation 1.5 students (G 1.5), Singhal (2004) stresses the importance of ensuring that non-traditional ESL learners know the standard of academic English. Non-traditional is a common term used in the literature to contrast native-born or long-term ELLs with their foreign-born counterparts, who are often referred to as traditional ESL students. In addition, teachers must clearly define this standard of writing. Yet little is straightforward or one-dimensional about this register because it "includes multiple, dynamic, inter-related competencies" (Scarella, 2003, p. 7). According to Swales (1990), one such competence is writing at the level of the "academic discourse community," a "socio-rhetorical network that forms to work towards sets of common goals" (p. 9). The important characteristic of these discourse communities is that "their established members" are familiar with "the particular genres that are used in the communicative furtherance of those set goals" (p. 9). Baynham (1995, cited in Hinkel, 2002) maintains that novices (NNES writers) are expected to become effective essay-writers in the academic discourse community through adaptation to specific discourse conventions. Academically motivated ELLs who are unable to pass an English-language proficiency test are equally unable to learn unfamiliar discourse or rhetorical conventions to gain acceptance into an undergraduate degree program.

\section{Rationale: Purpose and Objectives of the Study}

As Harklau, Losey, and Siegal's (1999) research shows, Generation 1.5 students are increasing in number and graduating from US secondary schools with grades that fail to reflect their academic language preparedness for university work. Canada's Generation 1.5 students face a similar situation, so it is the aim of this study to identify some of the salient writing patterns and characteristics exhibited by a cohort of first-year Generation 1.5 Chinese students $(n=30)$ registered in the $U$ of $C$ during the 2007 fall to spring 2008 se- 
mester. A total of 90 essays were analyzed, 30 from each of the three LOR cohorts (see Table 3). Chinese is the largest L1 group represented in the population of NNES that struggles to pass the EWT at U of C (Douglas, 2010), so it is vital to investigate the writing abilities of Generation 1.5 Chinese freshmen students to integrate these CBC students into the $U$ of $C^{\prime}$ 's academic discourse community. By combining a discourse analytic and corpus-based methodology, the writing samples of this group of long-term students were compared with those of two later-arrival Chinese students' essays, also written in fulfillment of the $U$ of C's Effective Writing Requirement (EWR). The primary objective was to see if there were significant differences in these three groups of Chinese students' use of cohesive devices and if there is a relationship between LOR in Canada and these students' ability to construct cohesive and coherent essays.

\section{Standardized Assessment Measures of L2 Academic Writing}

Proficiency: The TEST of Written English (TWE) and the U of $C^{\prime}$ 's Effective Writing Test (EWT)

TOEFL is a prominent organization created with the specific purpose of assessing L2 writing proficiency of NNES students. Its Educational Testing Service (ETS), first introduced in 1986, designs, develops, and administers the Test of Written English (TWE). Similar to the TWE, the Alberta Universities' Writing Competence Test, known as the Effective Writing Test (EWT) and administered by the $U$ of $C$ from 1976 to 2009 is an exam that students take to demonstrate university-level academic writing proficiency. To pass the EWT, students write an expository essay of approximately 400 words on one of four given topics (see Appendix A) within a 21/2 hour period.

\section{EWT Evaluation Criteria}

Like the TWE, the EWT was rated holistically, and essays were evaluated using the following criteria: content, grammar, structure, paragraphs, word choice, spelling, and punctuation. The EWT essays were independently assessed by two raters (native-speaker instructors who worked at the Effective Writing Centre during the tenure of the EWT). In terms of inter-rater reliability, a third assessor was called on to grade the essays in the event of a discrepancy between the first two raters. Table 1 shows the four final grade assessments for the EWT. There were serious consequences for students who were unable to pass the EWT; if students who received a grade of $U$ or MU were not able to fulfill the EWR within the allotted year from the date of registration in their first-year program, they were not allowed to continue studies in the U of C (EFWR, 2003). 
Table 1

Overall EWT Assessment Guidelines (EFWR, 2003)

\begin{tabular}{ll} 
Final Grade & Assessment \\
\hline $\begin{array}{l}\text { Satisfactory (S) } \\
\text { Marginally Satisfactory (MS) }\end{array}$ & $\begin{array}{l}\text { Failure in less than one category } \\
\text { Failure in } 1 \text { or } 1 \frac{1}{2} \text { categories or scattered errors in several } \\
\text { categories }\end{array}$ \\
Marginally Unsatisfactory (MU) & $\begin{array}{l}\text { Failure in } 2 \text { or } 2^{1 / 2} \text { categories-including at least one full- } \\
\text { fail category }\end{array}$ \\
Unsatisfactory (U) & $\begin{array}{l}\text { Failure in } 3 \text { or more categories or insufficient length to } \\
\text { judge writing ability }\end{array}$
\end{tabular}

Adapted from Douglas (2010).

\section{Theoretical Framework: The Role of Text Cohesion in English}

In the light of the above discussion about the standardized writing criteria of the TWE and the U of C's EWT constructs, cohesion was chosen as the primary criterion to investigate analyzing the expository essays of Chinese-background students who wrote the EWT in 2007-2008. Halliday and Hasan's (1976) seminal publication Cohesion in English is predicated on the notion that linking ideas results in the creation of discourse deemed to be coherent. This concept of cohesion is fundamental to understanding how language, written discourse, functions or "hangs together" (p. 8) through the use of cohesive ties or chains that link the presupposing and the presupposed across sentence boundaries. According to this framework, cohesion is achieved when the various types of semantic relationships created by a writer's choice of vocabulary and grammatical structures (pronouns, conjunctions, lexical substitutions, and occurrences of related lexical items) function together to produce "a basic unit of meaning in language" (p. 25) that is an authentic, complete, contextually relevant, and interpretable instance of discourse.

\section{Cohesion as a Measure of (L2) Academic Discourse Compe- tence and a Possible Function of LOR}

In the context of L2 writing pedagogy, Halliday and Hasan's (1976) theory of cohesion has led to significant developments in English-language teaching (ELT). For example, their concept of a cohesive tie established the usefulness of measuring a writer's linguistic competence by identifying and coding the presence of discourse markers systematically and quantifiably. In simplified terms, linguistic competence here refers to a writer's familiarity with grammar rules at a sentence level, syntax, semantics, and lexicon; this type of competence falls within the larger theory communicative competence posited by 
Hymes (1974). According to Halliday and Hasan, "the concept of a tie makes it possible to analyze a text in terms of its cohesive properties, and give a systematic account of its patterns of texture" (p. 4). Following Halliday and Hasan's publication, interest in how cohesion markers contribute to the flow of discourse increased. Teachers and writing instructors assess their (L2) students' knowledge of textual strategies by examining cohesive devices such as lexical and grammatical structures that "enable readers or listeners to make the relevant connections between what was said, is being said, and will be said" (Castro, 2004, p. 215). According to Cox, Shanahan, and Sulzby (1990, as cited in Palmer, 1999), "cohesion is important both to the reader in constructing the meaning from a text and to the writer in creating a text that can be easily comprehended" (p. 49). The difficulty in assessing ESL compositions lies in a perceived lack of fluency or connectedness that may lead an NS rater to find foreignness in the writing (Eggington \& Ricento, 1983), which may result in a low grade that fails to reflect accurately the students' full linguistic abilities, especially when the writing is produced under time constraints. To increase understanding of the nature of these linguistic abilities, in this study I investigated how three AOA groups of first-year students (whose L1 was either Cantonese or Mandarin) used lexical and reference cohesion markers.

\section{Lexical Cohesion as a Measure of L2 Vocabulary Proficiency}

As the number and range of earlier studies have shown, one research area in the broader domain of L2 vocabulary acquisition is lexical cohesion. Halliday and Hasan (1976) define lexical cohesion as "the cohesive effect achieved by the selection of vocabulary by means of reiteration or by collocation" (p. 274). Whereas reiteration and collocation are the two main categories that comprise lexical cohesion, only reiteration is examined in this study. Lexical reiteration is a mechanism of textual cohesion produced by the repetition of two or more lexical items that are observable at the surface of the text. In reiteration are four subcategories: "the repetition of a lexical item at one end of the scale; the use of a general word to refer back to a lexical item at the other end of the scale; and a number of things in between - the use of a synonym, or superordinate" (p. 278). Table 2 shows Halliday and Hasan's classification of lexical reiteration. The table shows four of Halliday and Hasan's lexical cohesion subcategories. In this study only three of the four types were examined: synonyms, superordinates, and general nouns. Also, reference cohesion markers, namely, personal pronouns and demonstratives (see Table 6) were included as key lexical items of cohesion analysis. Various salient lexical diversity and syntactic variables or measures were also included to provide for a more multidimensional analysis. 
Table 2

Halliday and Hasan's Lexical Cohesion Categories

Categories of Lexical Cohesion

(Halliday \& Hasan, 1976)

\begin{tabular}{lll}
\hline Category & Subcategory & Sub-subcategory \\
\hline Lexical Cohesion & Synonymy & Repetition; \\
& Synonym / Near-synonym; \\
& Superordinate; \\
& General Word \\
& Collocation & \\
\hline
\end{tabular}

Moreover, many studies indicate a positive effect of vocabulary on the quality of writing (Engber, 1995; Laufer, 1994; Lee, 2002). In the context of NNES university-level writing, Santos (1988, cited in Hinkel, 2004) found that lexical errors were considered the most serious in professors' evaluations of NNES students' writing, followed by problems with discourse and information organization and syntactic errors, with matters of content considered least important of all. Other studies show that lexical cohesion correlates with compositions scored holistically (Lieber, 1981; Meisuo, 2000; Witte \& Faigley, 1981; Yang, 1989). These studies suggest that positive correlation results from knowledge of the appropriate use of vocabulary in addressing specific topics in specific genres to produce cohesive and coherent writing. Coherence is a complex and controversial phenomenon. According to Halliday and Hasan (1976), text cohesion leads to greater text coherence; however, they also maintain that neither of these two conditions is sufficient without the other, nor does one by necessity entail the other.

\section{Research Design and Methodology}

This study combines the techniques of discourse analysis (DA) with a corpus linguistic approach to analyzing the written compositions of first-year university Chinese ELLs. Here discourse analysis refers to a descriptive linguistic approach that focuses on "language in actual use" (Kaplan \& Grabe, 2002). In the context of this study, a learner corpus comprised the language in use or authentic data that were analyzed. The 90 student essays were digitized and saved in plain-text format; then each was put through a concordancer to determine the frequency of synonyms, superordinates, and general nouns. To determine whether three LOR groups of Chinese students employed lexical and referential cohesion markers differently and to what degree, the data were analyzed using both manual hand counts and concordancing methods, 
namely, lexical profiling and key-word-search functions. The concordancer program was Cobb's Compleat Lexical Tutor or LexTutor, a publicly accessible Web site (http:/ / www.lextutor.ca/) that offers a variety of tools for analyzing digitized texts. The application of these multiple methods ensured a rigorous and systematic approach in conducting a data-driven, mixed-methods study that involves quantitative and qualitative techniques. The first step in the quantitative analysis was to determine whether there were any statistically significant differences in the three AOA cohorts of Chinese student writers' use of synonyms, superordinates, and general/enumerative nouns. Frequency data were compared across the three groups of student writers. The same procedure was used for personal and demonstrative pronouns, the two reference cohesion markers selected for analysis. The second step entailed conducting a discriminant function analysis to determine which variables differentiated the essays that received a passing score from those that failed (for statistical analysis, the EWT scores were categorized as either a pass or a no pass.) Further statistical analysis was subsequently performed for the variable(s) found to have significant interaction with the EWT mean scores. For the objectives of this study, the students' writing proficiency levels are defined by and based on the holistic scores given by the instructors at the $U$ of C's Effective Writing Centre, who graded the essays.

\section{Research Questions}

The three broad research questions that guided this investigation were:

1. What salient features of cohesion are demonstrated in the academic writing samples of three cohorts of first-year university Chinese-background ELLs with varying lengths of residence in Canada?

2. What is the relationship between length of residence in Canada and these three cohorts of Chinese students' use of lexico-grammatical markers on a university-administered test in written English proficiency?

3. Is there a relationship between the use of these markers and scores on the writing test?

\section{The Student Writers and L1 of the Three Cohorts}

Tables 3 and 4 show the three cohorts' average LOR and L1. In compiling the corpus for this study, I decided that 30 papers for each sub-corpus was a necessary sample size to establish representativeness and generalization. Ensuring the same number of each sub-corpus provides for a well-balanced sample. In addition, statisticians have found that it takes a sample size of about 30 to test the assumption that the variances of each group are homogeneous (Salkind, 2004). 
Table 3

Average LOR of the Three Student-Writer Cohorts

\begin{tabular}{lccc}
\hline $\begin{array}{l}\text { Student Group / } \\
\text { Cohort }\end{array}$ & $\begin{array}{c}\text { Total \# of } \\
\text { students / cohort }\end{array}$ & $\begin{array}{c}\text { LOR in } \\
\text { (\# of yrs.) }\end{array}$ & $\begin{array}{c}\text { Average LOR } \\
\text { (\# of yrs.) }\end{array}$ \\
\hline CBC (G 1.5) & 30 & $16-19$ & 17.5 \\
Early AOAs & 30 & $6-13$ & 9.4 \\
Late AOAs & 30 & $1-5$ & 3.1 \\
\hline
\end{tabular}

Table 4

L1 of the Three LOR Cohorts

\begin{tabular}{lccc}
\hline Student-Writers' $L 1$ & CBC G 1.5 & Early AOA & Late AOA \\
\hline Chinese (Mandarin) & 18 & 22 & 27 \\
Cantonese & 12 & 8 & 3 \\
\hline
\end{tabular}

Table 5 shows the relevant statistics for each sub-corpus.

Table 5

Corpus Data by LOR in Canada

\begin{tabular}{lccc}
\hline Corpus Data & $\begin{array}{c}\text { G 1.5 } \\
16-19 \text { yrs. LOR }\end{array}$ & $\begin{array}{l}\text { Early Arrivals: } \\
6-13 \text { yrs. LOR }\end{array}$ & $\begin{array}{c}\text { Late Arrivals: } \\
1-5 \text { yrs. LOR }\end{array}$ \\
\hline $\begin{array}{l}\text { \# of Essays } \\
\begin{array}{l}\text { Total \# of Tokens } \\
\text { (running words) in } \\
\text { each sub-corpus }\end{array}\end{array}$ & 30 & 30 & 30 \\
$\begin{array}{l}\text { Avg. \# of Tokens } \\
\text { per essay }\end{array}$ & 17,230 & 17,102 & 14,936 \\
\hline
\end{tabular}

\section{Results and Discussion}

As Kaplan (1988) states, "text is a complex multidimensional structure, and ... the dimensions involved include at least syntactic, semantic, and discoursal features" (p. 279). In the light of this view that text is a multidimensional construct, a variety of text analysis variables are included to understand how Chinese-background students apply lexical and reference cohesion devices in their EWT compositions. To this end, the quantitative analysis of this study 
was based on a similar categorization scheme of prevalent L2 text features established by researchers (Biber, 1995; Grant \& Ginther, 2000). As shown in Table 6, a total of 13 text features/variables were identified, counted, categorized, and analyzed.

A discriminant function analysis was performed to ascertain how well these 12 variables distinguished the Marginally Satisfactory essays from those that were Unsatisfactory. Results showed that synonymy and percentage of content words were the top two predictors of a passing (Marginally Satisfactory) score of 3 on the EWT. For statistical analysis, the 90 essays were sorted into two groups based on the holistic EWT score, coded as either a pass $(n=24)$ or no pass $(n=66)$. Results from the discriminant analysis demonstrated that the 12 text variables distinguished the pass and no-pass essays

Table 6

Text Features Counted by Hand and Tagged by Concordancer(s)

Text Features/Variables

1. Lexical Cohesion Discourse Markers
a. Synonyms
b. Hyponyms
c. Enumerative Nouns

2. Reference Cohesion Markers
a. \% of Personal Pronouns (First, Second, and Third-person)
b. \% of Demonstratives (This, That,${ }^{1}$ These, Those)

3. Lexical Diversity Measures
a. Type-token Ratio
b. \% of Function Words
c. $\%$ of Content Words
d. $\%$ of $\mathrm{K} 1$ Words
e. $\%$ of AWL Words

4. Text / Syntactic Variables
a. Essay Length (or 'scribal fluency' measure)
b. Total number of sentences
c. Average number of words per sentence ${ }^{2}$

\footnotetext{
${ }^{1}$ The concordancer tagging of That was carefully checked by hand in order to eliminate the inclusion of the demonstrative pronoun used as a subordinator, relative pronoun, or complement.

2 This syntactic variable was excluded from the discriminant analysis. The assumption of normality was not met; and because 5 extreme/outlier cases were removed to obtain a normal distribution, this variable was deemed unreliable.
} 
with 78\% accuracy. The IBM SPSS Statistics 19 discriminant function analysis used in this study reports the results of multiple $F$ tests (Wilks' lambdas), one for each predictor variable. However, these $F$ tests should not be confused with normal $F$ tests associated with ANOVA procedures. Moreover, the results indicate that two of the 12 text variables-synonyms and content words-show significant differences between the pass and no-pass essays. In other words, synonyms and content words seemed to be the differentiating variables that distinguished the EWT essays that received a satisfactory score of 3 (Marginally Satisfactory) and those that were graded as 2 (Marginally Unsatisfactory), or 1 (Unsatisfactory). The means and standard deviations of the 12 variables are presented in Table 7.

Because synonymy and content words were the two differentiating variables of a pass score of 3 on the EWT, an ANOVA was run to further test for statistically significant differences between the means of these two variables in distinguishing the pass $(n=24)$ from no-pass $(n=66)$ essays. Table 8 shows the ANOVA results.

Table 7

Means and Standard Deviations of the Twelve Text Variables Analyzed

\begin{tabular}{lcccccc}
\hline & \multicolumn{2}{c}{ Group 1 } & \multicolumn{2}{c}{ Group 2 } & \multicolumn{2}{c}{ Group 3 } \\
\hline Variable & $M$ & $S D$ & $M$ & $S D$ & $M$ & $S D$ \\
\hline Synonyms & 7.17 & 3.68 & 6.33 & 5.09 & 4.00 & 2.56 \\
Hypernyms & 6.00 & 3.67 & 6.30 & 3.11 & 4.90 & 2.14 \\
Enumerative Nouns & 4.70 & 4.18 & 2.30 & 1.77 & 2.27 & 2.30 \\
Personal Pronouns & 34.90 & 22.23 & 34.33 & 22.10 & 34.33 & 18.74 \\
Demonstratives & 7.53 & 4.75 & 8.07 & 4.77 & 5.30 & 2.98 \\
Type-Token Ratio & 0.40 & 0.48 & 0.40 & 0.05 & 0.42 & 0.05 \\
Function Words & 48.13 & 4.39 & 49.08 & 4.57 & 48.03 & 4.23 \\
Content Words & 33.32 & 4.09 & 35.21 & 4.32 & 36.14 & 4.73 \\
K1 Words & 81.48 & 5.16 & 84.29 & 3.82 & 84.21 & 4.60 \\
AWL & 6.58 & 2.62 & 5.34 & 2.52 & 5.45 & 2.86 \\
Essay Length & 574.33 & 135.82 & 570.07 & 159.42 & 497.87 & 116.96 \\
Number of & 29.07 & 6.491 & 26.97 & 5.16 & 29.27 & 11.06 \\
Sentences & & & & & & \\
\hline
\end{tabular}

Note. Group 1= CBC G 1.5, Group 2 = Early Arrivals, Group 3 = Late Arrivals. 
Table 8

Results of ANOVA for Synonyms and Content Words

\begin{tabular}{lccc}
\hline $\begin{array}{l}\text { Source } \\
\text { Dependent Variables: }\end{array}$ & $F$ & $d f$ & $P$ \\
\hline EWT scores (Pass Essays) & & & \\
Overall Effect: & 10.927 & 2,87 & .000 \\
Synonyms & 15.614 & 1,88 & .000 \\
Content Words & 9.305 & 1,88 & .003 \\
\hline
\end{tabular}

$p<0.05$.

The ANOVA results reported in Table 8 reveal a statistically significant difference $(p=0.00)$ in the synonym means for the pass essays $(M=8.46, S D=4.19)$ and no-pass essays $(M=4.88, S D=3.65)$. The synonym means for the 24 pass essays is almost double that of the 66 no-pass essays.

\section{Synthesis of Statistical Findings}

The statistical findings presented above suggest that the Generation 1.5 writers are a unique group of L2 writers whose productive knowledge of lexical cohesion devices, especially use of synonymy, warrants further investigation. As Liu (2000) points out, whereas content lexical ties such as repetition, superordinates/hypernymy, and synonymy are all essential elements in the teaching of text cohesion, synonymy is an underemphasized cohesive device when compared with explicit functional connectives on which some composition textbooks focus in her study comparing the academic writing abilities of traditional ESL students with those of college-level Generation 1.5 writers. Connerty (2009) concludes that the Generation 1.5 students may be "in a kind of developmental limbo where they struggle with mastering elements of language and discourse" (p. 111). The statistical results suggest that a closer look at Generation 1.5 learners' use of various lexical cohesion devices may reveal interesting findings about this profile of L2 students' discourse-producing strategies. In the final section of this study, a close textual analysis of a case study Generation 1.5 essay (Figure 1) reveals patterns relating to how a CBC Generation 1.5 student-writer establishes a cohesive and coherent essay using well-chosen lexical items and synonymous references.

The writing prompt to which the student-writer responded is shown verbatim as follows; hereafter referred to as the bully prompt.

Incidents of bullying and other types of violence seem to be on the rise in schools. What factors do you think contribute to this problem? (Appendix A). 
[1] (1) Bullying is the act of intimidating or harming other individuals for one's selfish gain of popularity, approval and / or self-confidence. (2) These acts of violence can escalate from school yard bullying to high school shootings. (3) Violence is increasing in schools, and are often the reactions of troubled individuals. (4) For instance, children who were victims of violence may victimize other individuals as a means of communicating their pain. (5) Acts of violence may also stem from peer pressure or depression, as over powering weaker individuals provide bullies with a sense of confidence and popularity. (6) As well, bullies may be taught to act in this manner, which results in individuals with violent behaviors. (7) In order to reduce the growing rate of violence in schools, these factors and problems need to be resolved and eliminated to achieve peace.

[2] (8) School is a place of learning, friendly interaction and a safe haven for individuals. (9) However, violence is often introduced to schools due to children experiencing domestic violence. (10) Children whom are victimized at home would feel weak and insignificant. (11) As a result, these victims would bully other individuals to gain confidence or as a means of expressing their pain. (12) Being feared by their peers would provide them with a sense of power and control in the school yard, which hides their pain and weakness. (13) This problem can be corrected by having parents not release their anger and frustration by bullying their children. (14) Rather, parents should be role models and encourage good behavior. (15) Reducing this factor from home would reduce the number of violent acts in schools, and destroy the cycle of violence. (16) However, bullies are not always victims of violent crimes, but violent characteristics may develop from exterior stresses. (17) Individuals need an outlet to release their frustration or depression. (18) Some of these individuals might turn to violence to express their feelings. (19) For example, the incident of the Virginia Tech shooting was the result of a troubled individual. (20) School related stresses and depression may have caused the young individual to act in this manner. (21) He expressed his frustration by means of hurting others and eventually ended his own life to terminate his pain. (22) Little was known about this character, so pressure to be accepted by his peers and society could have contributed to his actions. (23) Therefore, exterior stresses and pressures can cause an increase of violence in school when they are not properly resolved.

[3] (24) Besides exterior motives, bullying and violence can stem from individuals who were taught to act in this manner. (25) Children soldiers are an example of these horrific teachings. (26) These children were taught to kill threats rather than use peaceful negotiation to solve con- 
flicts. (27) Children soldiers spread these violent teachings to classmates and friends, as they believe they are being good citizens of society. (28) Individuals with a similar mindset may perform these acts of violence to relieve their boredom. (29) These bullies need to be corrected of their judgment or require other activities to occupy their time and reduce violent behaviour.

[4] (30) Bullying and violence benefits neither the bullies nor the victims. (31) However, violence is increasing in schools due to factors stemming from bullies themselves. (32) For instance, victims bully others to achieve self esteem, but are also continuing the cycle of violence to other individuals. (33) Personal problems like school stress and peer pressure can cause individuals to lash out at others. (34) As well, wrongful teachings impair personal values and judgment. (35) While others require a means of reducing their boredom, which may lead to bullying. (36) In the end, these factors need to be reduced or eliminated to decrease the level of violence in schools and society. (37) As world peace is achieved with small steps at home.

Figure 1. Case study essay A.

The EWT instructions sheet states the following.

No question requires special knowledge. None has a right answer, though your response must be directed to the question. Support your views and opinions by drawing on your personal experience, reading, prior coursework, or any other appropriate resources (see Appendix A).

This set of instructions about the nature of the writing task is important to note because it specifically provides the student writers with what appears to be a preferred rhetorical approach as to how the EWT essay question might be answered.

\section{A Look at Semantic Coherence in Case Study Essay A}

To frame discussion about the cohesive/anaphoric features found in this case study Generation 1.5 essay, it is vital to note that the fundamental assumption about language use is that coherence is related to the reader's interpretation of linguistic messages and that for readers, the background assumptions made about the normality of the world spring from "a mass of below-conscious expectations" (Brown \& Yule, 1983, p. 62). As noted above, coherence is a multifaceted area of investigation in both L1 and L2 discourse/composition studies, and it is often "considered an abstract, elusive and controver- 
sial concept that is difficult to teach and difficult to learn" (Connor \& Johns, 1990, p. 1). For this reason, I include only one type of reader-based coherence in my analysis, Enkvist's (1990) definition of semantic coherence, explained below. According to Brown and Yule (1983), it is these expectations that influence understanding of what constitutes coherent discourse. Further, the reader-based view of coherence adopted for this analysis is that the presence of intersentential or overt cohesive links do not necessarily make a text hang together (Halliday \& Hasan, 1976). Following Halliday and Hasan (1985), Parsons (1991), Lee (2002), and Louwerse (2004), the term cohesion is used to distinguish textual elements on which coherent texts are built and not to delineate a cause-effect relationship as critics of Halliday and Hasan's (1976) framework pointed out (Carrell, 1982; Steffensen, 1981; Tierney \& Mosenthal, 1983). My textual analysis of case study essay A supports the view that cohesion is "an essential feature of a text judged to be coherent" (Parsons, p. 415). The key word is judged because it implicates the role of the reader in interpreting and deriving meaning from a written text. The role of the reader is fundamental to an analysis of coherence, especially in terms of defining what proficient or satisfactory writing entails or writing perceived to be proficient and judged satisfactory according to the EWT grading scheme.

In analyzing case study essay $\mathrm{A}$, it is noteworthy that the first sentence indicates the student-writer's lexical range. The essay begins with a definition of bullying as "the act of intimidating or harming other individuals for one's selfish gain of popularity, approval and/or self-confidence." The words intimidating and harming, in addition to popularity and approval, set an impression of the student's lexical maturity and sense of overt cohesiveness resulting from the precise choice of lexical items. For example, the word intimidating (1) forms a cohesive tie with overpowering in sentence 5; and in sentence 4 , the verb victimize suggests the student's knowledge/familiarity with how synonyms carry varying degrees or shades of meaning and nuances. Student A's use of harming, intimidating, overpowering, and victimize signal verb choices that form a lexical chain of semantic meaning to connote degrees of severity and define the student's belief about the motives for bullying. Similarly, the verb escalate (2) establishes a cohesive tie with increasing in sentence 3 and the reference to "growing rate of violence" in sentence 6. Other examples of anaphoric cohesive ties include the explicit reference to children as victims of violence (4), as in those troubled individuals (3) who turn out to be bullies (6) "taught to act in this manner" (6).

More cohesive ties emerge as the essay's argument develops through a series of synonymous inflections such as acts of violence (5), followed by the cataphoric reference to violent behaviors (6). Later the student explains that exterior stresses (16) may be the cause of violent characteristics (16), which is a salient anaphoric reference to the earlier mentions of acts of violence (5) and violent behaviors (6). In terms of lexical cohesion, it is evident that this essay 
features a variety of well-chosen words and phrases with similar semantic meanings and connotations. The reference to victims communicating their pain (4), expressing their pain (11), and need[ing] an outlet to release their frustration or depression (17) creates an overall sense of textual cohesion and provides semantic coherence. As a result, student A's lexical choices and configurations project a sophisticated level of productive vocabulary knowledge.

\section{Collocations as a Sign of Native-like Fluency in Case Study Essay A}

In the passage shown below, student $\mathrm{A}$ uses a series of collocations (underlined) to reinforce the argument presented.

(10) Children whom are victimized at home would feel weak and insignificant.(11) As a result, these victims would bully other individuals to gain confidence or as a means of expressing their pain.(12) Being feared by their peers would provide them with a sense of power and control in the school yard, which hides their pain and weakness. (13)This problem can be corrected by having parents not release their anger and frustration by bullying their children. (14) Rather, parents should be role models and encourage good behavior. (15) Reducing this factor from home would reduce the number of violent acts in schools, and destroy the cycle of violence.

The presence of collocational phrases, such as weak and insignificant, power and control, pain and weakness, anger and frustration, and cycle of violence indicate signs of a mature 18-year-old ESL student-writer. The passage denotes almost native-like fluency with the student's use of a series of appropriately chosen collocational items and the metaphoric reference in sentence 15 to destroy[ing] that cycle of violence.

Although the singular demonstrative pronoun this is ambiguously and inaccurately used in sentences 13 and 14 to highlight more than one referential point at once, the student's ability to establish a consistent sense of textual cohesion through effective choice of lexical alternatives is noted. For example, the student states the need to destroy the cycle of violence (15), an anaphoric reference to the preceding assertion that this problem can be corrected (13). In providing further propositional support for his argument, student A uses the example of the Virginia Tech shooter being a troubled individual who ended his own life to terminate his pain (21). The synonyms ended and terminated form a cohesive tie in the same sentence to indicate the student's productive knowledge of lexical substitutes and emphasize an argument/proposition.

\section{A Look at How Generation 1.5 Essay A Hangs Together vis-à-vis Semantic Coherence}

A closer look at case study essay A reveals cohesive, semantic relations that establish a sense of logical continuity in the text. The reference to exterior stresses (23) forms a cohesive tie with the cataphoric reference to exterior motives (24) 
in the opening sentence of paragraph 3 . These cohesive ties have the overall effect of orienting the reader toward semantic coherence. I refer in particular to my own reader's sense of how this Generation 1.5 essay hangs together (Halliday \& Hasan, 1976, p. 8) in a logical, interpretable way. According to Halliday and Hasan, this quality of hanging together has everything to do with the reader's impression of what makes a text coherent. In the final section of this qualitative analysis, I explore how case study essay A uses lexical cohesion, namely, synonymy, as an effective text-building device in constructing a coherent essay response.

Adapting Enkvist's (1990) definition of overall textual coherence to an analysis of essay A, I focus on the last two paragraphs of this Generation 1.5 essay to show how the student-writer uses overt lexical links and effective cohesive ties to build a "consistent world picture" (p. 14), one that is "summarizable and interpretable" in the reader's mind (p. 14). The extract below captures the first three sentences of paragraph 3 .

(24) Besides exterior motives, bullying and violence can stem from individuals who were taught to act in this manner. (25) Children soldiers are an example of these horrific teachings. (26) These children were taught to kill threats rather than use peaceful negotiation to solve conflicts. (27) Children soldiers spread these violent teachings to classmates and friends, as they believe they are being good citizens of society.

The reference to these horrific teachings (25) refers cataphorically to violent teachings (27) two sentences later. Horrific and violent constitute a lexical tie. Further, teachings (25) refers to taught (24) in the previous sentence, forming another lexical tie. In the concluding paragraph of this essay, student A states the following: As well, wrongful teachings impair personal values and judgment (34). Although the use of lexical cohesion shown here in conjunction with repetition is not carried out, it is important to acknowledge that the studentwriter nonetheless establishes consistency or semantic coherence. The repeated references to horrific teachings (34), violent teachings (27), and wrongful teachings (34) suggest an attempt to incorporate a variety of lexical substitutes/synonyms to reinforce an argument that is interpretable as a consistent world picture woven with multiple cross-references that integrate other sentences in the essay.

In applying Enkvist's (1990) "consistent world picture" (p. 14) definition of coherence. I arrived at a meaningful and coherently summarizable reading of Generation 1.5 essay A, especially in interpreting and identifying with the student-writer's understanding of an issue that affects society (37). The student opens the issue of bullying by including knowledge of Children soldiers (25), those troubled individual[s] $(3,19)$ whom the student believes were taught to kill threats rather than use peaceful negotiation to solve conflicts (26). In analyzing the student's assertions, which range from a discussion of bullying on a 
local playground to an example of child soldiers in the world or society, it seems that student A demonstrates a reasonable understanding of how various societal factors contribute to the problem of bullying in schools (EWT bully prompt wording, verbatim; see Appendix A).

Further, through use of propositional or ideational content, the student demonstrates a mature and objectively analytical rhetorical approach to answering the bully prompt essay question What factors do you think contribute to this problem? In directly addressing this problem, the student begins the essay by explaining in paragraph 1 how the problem can escalate from school yard bullying to high school shootings (2) to the Virginia Tech shooting (incident resulting from the actions of) a troubled individual (19) to the horrific and violent case of children soldiers who were taught to kill (26). The assertion that child soldiers spread these violent teachings to classmates and friends (27) betrays a novice world knowledge and indicates a gap in knowledge about sociopolitical forces, factors, and complexities that underlie the indoctrination of child soldiers in Africa. Still, the example of children soldiers creates a coherent frame of reference because of its semantic coherence instantiated through the appropriate and effective synonymous references, such as horrific and violent teachings (27) as well as violent behaviour (29), which impair personal values and judgment (34).

In the concluding paragraph of the essay, the student ends by stating, world peace is achieved with small steps at home (37). This final sentence reinforces a semantic/ideational coherence, a consistent world picture, because the references to world peace and home reiterate and reinforce student A's argument that bullying and the ensuing violence begin locally and escalate globally.

As for the rhetorical approach to answering the EWT question, student A avoided the use of the first-person pronoun I. Thus Essay A demonstrates a depersonalized rhetorical approach that indicates the student-writer's awareness of certain academic writing conventions such as the expectation for the writer to maintain a distanced, objective, and impersonal stance, a rhetorical feature that characterizes expository or argumentation essays in the North American academic discourse community (Connerty, 2009; Hinkel, 2002). This finding suggests that an exploration of NNES student-writers' awareness of audience is yet another area of investigation, using methods of discourse analysis, that could provide understanding of discoursal tendencies/productive knowledge of Generation 1.5 writers. In summarizing the insights gained from this qualitative analysis, a close textual analysis of the lexical choices and use of synonymy shown in a case study essay reveal patterns indicative of the student's ability to create an interpretable and summarizable body of semantic coherence.

\section{Ongoing Implications for Future Research and ESL Teaching}

The findings and insights presented in this research study contribute to the developing literature on Canadian-born Generation 1.5 ELLs. Through com- 
piling, comparing, and analyzing 13 salient textual features of three LOR groups of Chinese-background students' writing samples and a case study of one CBC Generation 1.5 student's essay, it is shown that an extended LOR affects how some Canadian-born Chinese ESL students use discourse-production strategies in their academic writing. Although circumstantial factors such as student-background variables were excluded, this study concurs in findings of other researchers on Generation 1.5 students and suggests that the academic writing needs of long-term Canadian-born ELLs are distinct from those of traditional ESL or foreign-born students.

In summary, versatile, open-minded, empathetic, and explicit teaching is required to address fully the English-language-learning needs of Generation 1.5 students if ESL teachers are to facilitate the learning of competent ELLs as they make strides to gain entry and membership into the North American academic discourse community. This research represents a step in expanding the understanding of Generation 1.5 learners and investing in the teaching of these multiliterate university-bound students.

\section{The Author}

Krista Leo was born in Calgary, Alberta. She has worked extensively with Generation 1.5 students of Chinese background as well as international ESL learners. Her research interests include ESL writing pedagogy and discourse analysis. She received her master's TESL degree from the University of Calgary in 2011.

\section{References}

Benesch, S. (2001). Critical English for academic purposes: Theory, politics, and practice. Mahwah, NJ: Erlbaum.

Biber, D. (1995). Dimensions of register variation: A cross-linguistic comparison. Cambridge, UK: Cambridge University Press.

Boyd, M. (2002). Educational attainments of immigrant offspring: Success or segmented assimilation? International Migration Review, 36, 1037-1060.

Brown, G., \& Yule, G. (1983). Discourse analysis. Cambridge, UK: Cambridge University Press.

Canale, M., \& Swain, M. (1980). Theoretical bases of communicative approaches to second language teaching and testing. Applied Linguistics, 1, 1-47.

Carrell, P.L. (1982). Cohesion is not coherence. TESOL Quarterly, 16, 479-488.

Castro, C.D. (2004). Cohesion and the social construction of meaning in the essays of Filipino college students writing in L2 English. Asia Pacific Education Review, 5(2), 215-225.

Connerty, M.C. (2009). Variation in academic writing among Generation 1.5 learners, native English-speaking learners and ESL learners: The discoursal self of G1.5 student writers. Unpublished doctoral dissertation, University of Birmingham, UK.

Connor, U., \& Johns, A.M. (Eds.). (1990). Coherence in writing: Research and pedagogical perspectives. Alexandria, VA: TESOL.

Douglas, S.R. (2010). Non-native English speaking students at university: Lexical richness and academic success. Unpublished doctoral dissertation, University of Calgary.

EFWR. (2003). The assessors' guide for the effective writing test. Calgary, AB: University of Calgary, Effective Writing Programme.

Eggington, W., \& Ricento, T. (1983). Discourse analysis as a pedagogical tool. CATESOL Occasional Papers, 9, 74-85. 
Engber, C.A. (1995). The relationship of lexical proficiency to the quality of ESL compositions. Journal of Second Language Writing, 4, 139-155.

Enkvist, N.E. (1990). Seven problems in the study of coherence and interpretability. In U. Connor \& A.M. Johns (Eds.), Coherence in writing: Research and pedagogical perspectives (pp. 9-28). Alexandria, VA: Teachers of English to Speakers of Other Languages.

Grant, L., \& Ginther, A. (2000). Using computer-tagged linguistic features to describe L2 writing differences. Journal of Second Language Writing, 9, 123-145.

Halliday, M.A.K., \& Hasan, R. (1976). Cohesion in English. London: Longman.

Halliday, M.A.K., \& Hasan, R. (1985). Language, context, and text: Aspects of language in a socialsemiotic perspective. Geelong, VIC: Deakin University.

Harklau, L., Losey, K.M., \& Siegal, M. (Eds.). (1999). Generation 1.5 meets college composition: Issues in the teaching of writing to U.S.-educated learners of ESL. Mahwah, NJ: Erlbaum.

Hinkel, E. (2002). Second language writers' text: Linguistic and rhetorical features. Mahwah, NJ: Erlbaum.

Hinkel, E. (2004). Teaching academic ESL writing: Practical techniques in vocabulary and grammar. Mahwah, NJ: Erlbaum.

Hymes, D. (1974). Foundations in sociolinguistics: An ethnographic approach. Philadelphia, PA: University of Pennsylvania Press.

Kaplan, R.B. (1988). Contrastive rhetoric and second language learning: Notes towards a theory of contrastive rhetoric. In A. Purves (Ed.), Writing across languages and cultures: Issues in contrastive rhetoric (pp. 275-303). Newbury Park, CA: Sage.

Kaplan, R., \& Grabe, W. (2002). A modern history of written discourse analysis. Journal of Second Language Writing, 11(3), 191-223.

Laufer, B. (1994). The lexical profile of second language writing: Does it change over time? RELC Journal, 25(2), 21-33.

Lee, I. (2002). Teaching coherence to ESL students: A classroom inquiry. Journal of Second Language Writing, 11(2), 135-159.

Lieber, P.E. (1981). Cohesion in ESL students' expository writing: A descriptive study. Unpublished doctoral dissertation, New York University.

Liu, D. (2000). Writing cohesion: Using content lexical ties in ESOL. Forum, 38(1), 28-35.

Louwerse, M.M. (2004). Un modelo conciso de cohesion en el texto y coherencia en la comprehension. [A concise model of cohesion in text and coherence in comprehension]. Revista Signos, 37, 41-58.

Matsuda, P.K., Canagarajah, A.S., Harklau, L., Hyland, K., \& Warschauer, M. (2003). Changing currents in second language writing research: A colloquium. Journal of Second Language Writing, 12, 151-179.

McGinnis, S. (2008, December). Strong grasp of mother tongue boosts students. Calgary Herald. Available:

http:/ / www2.canada.com/calgaryherald/news/city / story.html?id=24198f20-2dc8-42c9bc4b-d829f085f291\&p=1

Meisuo, Z. (2000). Cohesive features in the expository writing of undergraduates in two Chinese universities. RELC Journal, 31(1), 61-95.

Palmer, J.C. (1999). Coherence and cohesion in the English language classroom: The use of lexical reiteration and pronominalisation. RELC Journal, 30(2), 61-85.

Parsons, G. (1991). Cohesion coherence: Scientific texts. In E. Ventola (Ed.), Functional and systemic linguistics: Approaches and uses (pp. 415-429). Berlin: Mouton de Gruyter.

Roessingh, H. (2008). Variability in ESL outcomes: The influence of age on arrival and length of residence on achievement in high school. TESL Canada Journal, 26, 87-107.

Roessingh, H., \& Elgie, S. (2009). Early language and literacy development among young English language learners: Preliminary insights from a longitudinal study. TESL Canada Journal, 26, 24-45. 
Rumbaut, R., \& Ima, K. (1988). The adaptation of Southeast Asian refugee youth: A comparative study. Available: ERIC database (ED299372).

Salkind, N.J. (2004). Statistics for people who (think they) hate statistics (2nd ed.). Thousand Oaks, CA: Sage.

Scarella, R. (2003). Academic English: A conceptual framework (Technical Report 2003-1). Irvine, CA: University of California Linguistic Minority Research Institute.

Singhal, M. (2004). Academic writing and Generation 1.5: Pedagogical goals and instructional issues in the college composition classroom. The Reading Matrix, 4(3), 1-13.

Steffensen, M.S. (1981). Register, cohesion, and cross-cultural reading comprehension (Technical Report No. 220). Champaign, IL: University of Illinois at Urbana-Champaign, Center for the Study of Reading.

Swales, J.M. (1990). Genre analysis: English in academic and research settings. Cambridge, UK: Cambridge University Press.

Tierney, R.J., \& Mosenthal, J.H. (1983). Cohesion and textual coherence. Research in the Teaching of English, 17, 215-229.

Valdés, G. (1992). Bilingual minorities and language issues in writing: Toward professionwide responses to a new challenge. Written Communication, 9(1), 85-136.

Witte, S.P., \& Faigley, L. (1981). Coherence, cohesion, and writing quality. College Composition and Communication, 32(2), 189-204.

Yang, W. (1989). Cohesive chains and writing quality. Word, 40(1-2), 235-254. 


\title{
Appendix A
}

\author{
THE ALBERTA UNIVERSITIES’ WRITING COMPETENCE TEST \\ THE UNIVERSITY OF CALGARY \\ EFFECTIVE WRITING TEST
}

Time: 2.5 hours

January 24, 2008

Choose ONE of the following questions and respond to it in a well-organized essay of approximately 400 words. If you write too little, your essay may be judged an inadequate sample of your work. Essays will not be failed for being more than the suggested length; however, writing much more than required will not necessarily improve your essay. No question requires special knowledge. None has a right answer, though your response must be directed to the question. Support your views and opinions by drawing on your personal experience, reading, prior coursework, or any other appropriate resources.

Markers are looking for university-level writing competence. Be sure to check your work for logical arguments, clear organization, well-developed paragraphs, well-constructed sentences, accurate word use, and correct grammar, spelling and punctuation. You may consult an English language dictionary; however, bilingual dictionaries (cg. French/English), thesauri, electronic translators, or other aids are not permitted.

Please write on every second line. If your essay is clear and legible, you are not expected to recopy it. HOWEVER, PLEASE CROSS OUT ANY WORK YOU DO NOT WANT MARKED: DO NOT TEAR PAGES OUT OF THE BOOKLET.

NOTE: The Alberta Universities' Writing Competence Test carries the same status as a final university examination. Accordingly, any form of cheating on the test will be considered grounds for suspension from the University. Proof of identity will be required during the test.

1. Should professors in all disciplines (e.g., those in business, engineering, history, kinesiology, psychology, and so forth) take spelling and grammar into account when marking student papers?

2. The Canadian government recently announced that it will reward Canadian athletes with $\$ 20,000$ for winning a gold medal at the Olympics, $\$ 15,000$ for a silver medal, and $\$ 10,000$ for a bronze medal. Do you think this new policy is a good one?

3. Canada welcomes many healthcare professionals immigrating from other countries; however, some have difficulty with the required language tests. Should doctors, nurses, pharmacists and other healthcare professionals immigrating to Canada have to pass a test in the use of the English language before they are allowed to practice their professions?

4. Incidents of bullying and other types of violence seem to be on the rise in schools. What factors do you think contribute to this problem?

Test results will be available through your Student Centre Link from the My $\mathrm{U}$ of $\mathrm{C}$ portal in four to five weeks. We recommend that you review your marked test with a Writing Centre instructor. You can book an appointment at http:/ / efwr.ucalgary.ca 